\title{
Quantas salas de cinema existiram no Brasil? Reflexões sobre a dimensão e características do circuito exibidor brasileiro
}

How many movie theaters were there in Brazil? Reflections on the dimension and characteristics of the Brazilian exhibition circuit

Rafael de Luna Freire ${ }^{1}$

Natasha Hernandez Almeida Zapata²

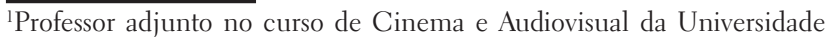
Federal Fluminense (UFF), no Programa de Pós-Graduação em Comunicação (PPGCOM - UFF) e no Programa de Pós-Graduação em Cinema e Audiovisual (PPGCine - UFF). E atualmente chefe do Departamento de Cinema e Vídeo da UFF. E-mail: rafaeldeluna@hotmail.com

${ }^{2}$ Doutoranda do PPGCOM - UFF. E-mail: nhernandezalmeida@gmail.com
} 
Resumo: diante da escassez de estudos sobre a história da exibição cinematográfica no Brasil, permanece uma lacuna relacionada às mudanças na dimensão do circuito exibidor brasileiro ao longo de grande parte do século XX. Este artigo tem como objetivo suprir essa lacuna, buscando construir um panorama mais concreto desse circuito através de dados que permitem criar uma estimativa do número de salas de cinema que já estiveram em funcionamento no Brasil. Buscando fontes inéditas ou pouco utilizadas pelos estudiosos do cinema brasileiro, foram alinhados dados diversos e, muitas vezes, conflitantes, que conduziram uma reflexão sobre suas origens, seu contexto, sua confiabilidade e suas limitações.

Palavras-chave: salas de cinema; circuito exibidor brasileiro; história do cinema; estatística.

Abstract: in face of the scarcity of studies on the history of film exhibition in Brazil, there remains a gap related to the changes in the size of the Brazilian exhibition circuit throughout much of the 20th century. This article aims to fill this gap, seeking to build a more concrete panorama of this circuit, through data that allowed us to estimate the number of cinemas that have already been in operation in Brazil. In search of sources that were not published or were not often used by the Brazilian film scholars, diverse and often conflicting data were aligned, which led to a reflection on its origins, its context, its reliability and its limitations.

Keywords: movie theaters; Brazilian exhibition circuit; cinema history; statistics. 
Apesar do vigor de estudos recentes sobre a economia do audiovisual e o mercado cinematográfico no país, em geral ainda são escassos os estudos mais aprofundados sobre a história do setor de exibição no Brasil. Além disso, as abordagens econômicas têm se resumido quase exclusivamente ao contexto posterior à criação da Empresa Brasileira de Filmes - Embrafilme, em 1969, concentrando-se majoritariamente no cenário dos anos 1990 em diante, a partir da criação das chamadas leis de incentivo fiscal e da constituição da Agência Nacional de Cinema - Ancine.

Uma das possíveis causas para a concentração de estudos no momento presente ou num passado recente seria a dificuldade de obtenção de dados de mercado de contextos históricos anteriores, seja em relação ao desempenho econômico dos filmes (resultados de bilheteria) ou ainda mais sobre a dimensão do circuito exibidor brasileiro (números de salas de cinema). Entretanto, raramente os estudiosos pesquisam em fontes outras que não as já largamente conhecidas e amplamente divulgadas, sendo invariavelmente citados os mesmos números fornecidos pela empresa privada Filme $\mathrm{B}^{3}$ ou os coletados e organizados pela Ancine.

Como resultado dessa concentração dos estudos e análises no cenário contemporâneo, a história do circuito exibidor brasileiro é frequentemente representada a partir de uma visão vaga e nostálgica do passado - evocada mais a partir de fotografias e relatos memorialísticos do que de fontes do governo ou do próprio setor exibidor. Não é raro resumir o contexto anterior aos anos 1970 como um período estanque, primordialmente caracterizado pelas saudosas salas de ruas e palácios de cinema, sobretudo em contraposição à crise do setor exibidor que se aprofundou justamente a partir da segunda metade da década de 1970. Ou seja, ocorre uma idealização ou, pelo menos, uma generalização de todo o cenário anterior à crise, que se arrastou por mais de duas décadas, até a reformulação do mercado exibidor brasileiro com a chegada dos grupos exibidores estrangeiros e do conceito de multiplex nos anos 1990.

Este artigo tem o objetivo de tentar suprir essa lacuna, buscando construir um panorama mais concreto do circuito exibidor cinematográfico brasileiro a partir dos anos 1930 (com a chegada do cinema sonoro) até a década de 1980 (período sobre o qual existem mais informações oficiais disponíveis). Um dos objetivos é reunir dados que permitam criar uma estimativa do número de salas de cinema em funcionamento no Brasil ao longo de grande parte do século XX, fornecendo subsídios para análises

${ }^{3}$ Com a extinção da Embrafilme e do Conselho Nacional de Cinema (Concine) pelo presidente Fernando Collor de Mello, em 1990, surgiu a necessidade de uma nova empresa capaz de catalogar dados referentes ao mercado cinematográfico no Brasil. Assim, em 1997, foi criada a Filme B, uma empresa especializada na coleta e análise de informação sobre o mercado cinematográfico. 
menos especulativas. Para alcançar tal fim, empreendemos um esforço de buscar fontes inéditas ou pouco utilizadas pelos estudiosos do cinema brasileiro. Como resultado, foram alinhados dados diversos e muitas vezes conflitantes, levando a uma reflexão sobre as origens dessas informações, seu contexto, sua confiabilidade e suas limitações.

\section{A retração do circuito exibidor após o advento do cinema sonoro}

O processo de introdução e difusão do cinema sonoro no Brasil pode ser definido como a gradual adoção do acompanhamento sonoro sincronizado mecanicamente como padrão de projeção cinematográfica no circuito exibidor nacional. Após o sucesso alcançado no mercado doméstico dos Estados Unidos, os grandes estúdios de Hollywood e os fabricantes de equipamentos se lançaram à promoção internacional da nova tecnologia, que chegou ao Brasil em abril de 1929, com a inauguração do Cine Paramount, em São Paulo. Essa foi a primeira sala de cinema da América do Sul a instalar os sistemas de projeção sonora Vitaphone (som em discos) e Movietone (som no filme).

A incorporação da reprodução sonora mecânica e sincrônica como elemento essencial da projeção de filmes impôs aos exibidores a compra de caros equipamentos, o treinamento e a contratação de funcionários, e o pagamento de taxas mensais de manutenção. Obrigou ainda os empresários a realizarem reformas estruturais nos espaços de exibição, tanto para regularizar o fornecimento de eletricidade aos equipamentos quanto para garantir melhor qualidade acústica. Os filmes falados em idiomas estrangeiros, mesmo que depois traduzidos para o português através das legendas, foram outro fator que afetou o negócio dos exibidores. Desse modo, parte em consequência do advento do som - assim como da crise econômica mundial após a queda da bolsa de Nova York -, o número de salas de cinema no Brasil reduziu sensivelmente ao longo dos anos 1930, concentrando-se nos grandes centros urbanos. A recuperação do circuito exibidor, com a retomada do crescimento do público, ocorreria somente na passagem para os anos 1940 (SOUZA; FREIRE, 2017) .

Um exemplo significativo do movimento de encolhimento do mercado exibidor brasileiro com o advento do cinema sonoro é o da cidade de Curitiba. Na capital paranaense, das cinco salas de cinema então existentes em 1930, três delas - dedicadas ao público mais popular - chegaram a fechar as portas e somente duas mantiveram-se em

\footnotetext{
${ }^{4}$ Uma reportagem da revista norte-americana Variety, publicada em fevereiro de 1936, sobre o mercado cinematográfico brasileiro informava que $33 \%$ das salas de exibição brasileiras estavam localizadas nas cinco maiores cidades do país (Rio de Janeiro, São Paulo, Salvador, Recife e Porto Alegre) e todos esses cinemas já estavam convertidos para o cinema sonoro. A mesma matéria dizia ter havido um encolhimento de $20 \%$ do mercado exibidor brasileiro em relação a 1928 (FIRST..., 1936, p. 22).
} 
funcionamento ininterrupto. Porém, em 1939, a capital do Paraná já contaria com seis salas de exibição operando regularmente (ALVETTI, 1989, p. 37-39).

No Rio de Janeiro, então capital federal, a tendência foi semelhante. Entre 1929 e 1930, havia 107 cinemas comerciais em funcionamento regular na cidade, número que se reduziu até 1932. A partir de então, porém, o circuito recobraria seu crescimento, com 108 salas funcionando já em 1934 e chegando ao auge da década em 1938, com 129 salas (GONZAGA, 1996, p. 337).

Como último exemplo, citamos a cidade de Niterói que, de oito salas, em 1929, chegou a ter apenas cinco cinemas sonoros em funcionamento por volta de 1934. Mas em 1940 o circuito niteroiense já tinha crescido novamente e a cidade tinha retornado ao patamar de oito salas (FREIRE, 2012, p. 100-145).

Confirmando essa tendência em caráter nacional, o Gráfico 1, elaborado através de fontes diversas - particularmente do anuário norte-americano Film Daily Yearbook -, deixa evidente a acentuada diminuição do circuito exibidor brasileiro, particularmente entre 1933 e 1935. Essa diminuição do circuito alguns anos após a chegada do cinema sonoro é mais significativa por ser possível indicar - mais através de relatos e reportagens do que de números - que o setor vinha crescendo intensamente na segunda metade dos anos 1920. Já na segunda metade da década da 1930, passada a fase mais difícil da transição para o sonoro, o circuito se estabilizou, mantendo-se razoavelmente constante, mas num patamar ainda inferior ao do início da década.

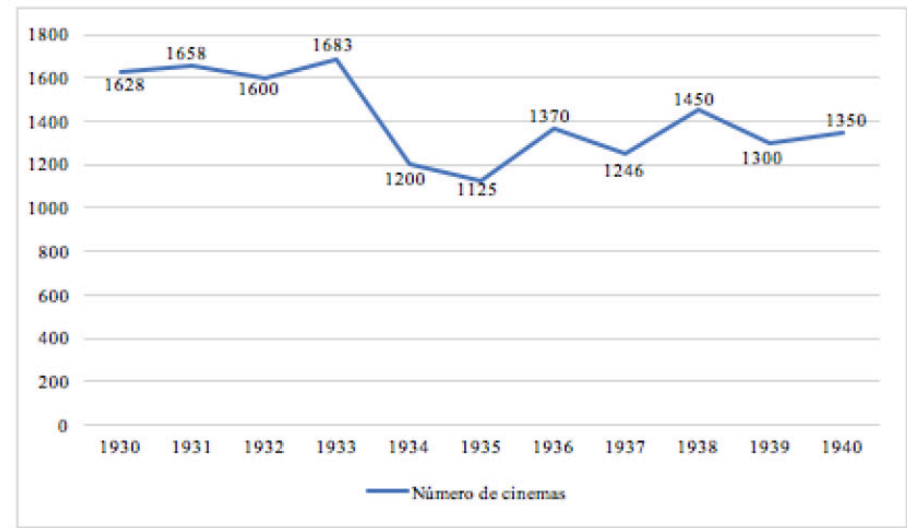

Gráfico 1: Evolução do número de salas de cinema no Brasil (1930-1940).

Fonte: Elaborado pelos autores (2017), com base em Souza e Freire (2017). 
Embora tenham sido utilizados dados retirados majoritariamente dos anuários da revista Film Daily ${ }^{5}$, poderiam ser usadas outras fontes para tentar atingir o mesmo objetivo. Uma questão metodológica fundamental refere-se, portanto, à eleição da fonte a ser utilizada, uma vez que é frequente a disparidade na estimativa de cinemas existentes no Brasil num mesmo ano conforme fornecido por fontes distintas.

Além disso, dificilmente é possível, para abranger um período mais longo, aterse a uma fonte somente, sendo preciso ter sensibilidade ao combinar dados de origens diferentes. Cabe ao historiador da exibição cinematográfica julgar quais são as informações mais críveis a partir da análise do contexto e da comparação das informações.

Para exemplificar esse problema, o Gráfico 2 é baseado no trabalho pioneiro de Takahashi (1985), talvez o primeiro a tentar estimar as mudanças no circuito exibidor brasileiro entre as décadas de 1940 e 1980, utilizando para isso dados oriundos do Instituto Brasileiro de Geografia e Estatística (IBGE), do Instituto Nacional de Cinema (INC) e da Embrafilme.

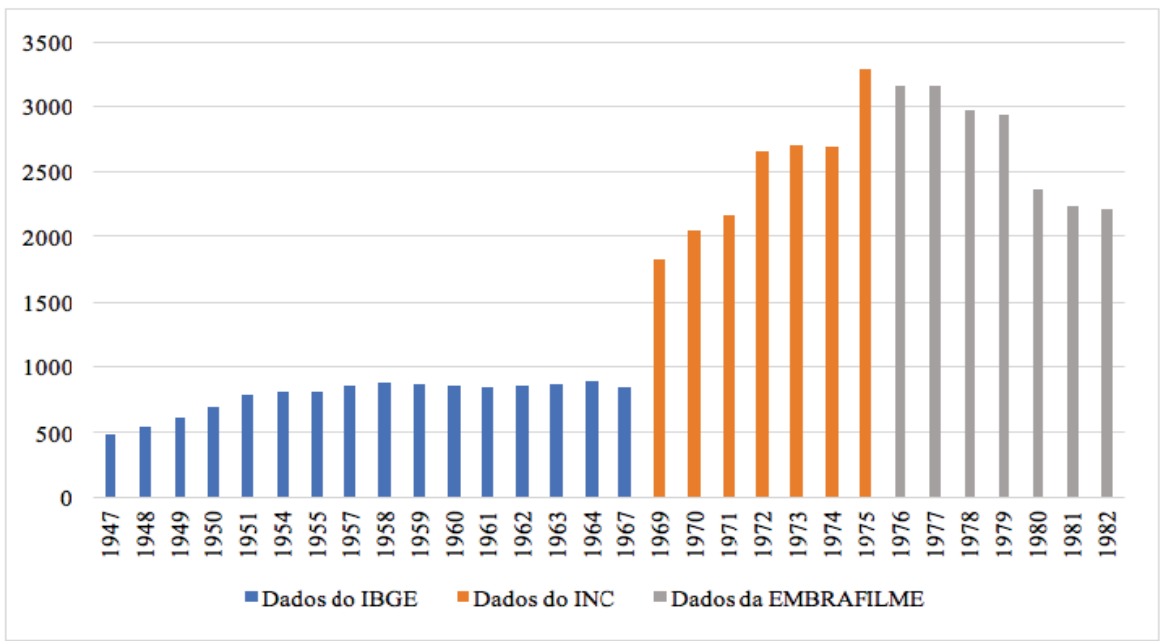

Gráfico 2: Evolução do número de salas de cinema do Brasil (1947-1982).

Fonte: Elaborado pelos autores (2017), com base em Takahashi (1985, p. 108).

\footnotetext{
${ }^{5} \mathrm{~A}$ origem dessas informações eram os relatórios produzidos pelo Departamento de Comércio Internacional do Governo dos Estados Unidos (SOUZA; FREIRE, 2017). A opção pelo uso dessas fontes se deu pela confirmação de sua confiabilidade no cotejo com dados originários de fontes diferentes, como revistas e jornais brasileiros.
} 
Deixando de lado, por enquanto, os dados relativos ao período entre 1969 e 1982, quase inteiramente idênticos aos que são até hoje divulgados pela Ancine para o mesmo período $^{6}$, podemos nos concentrar na análise dos dados do IBGE, de 1947 a 1967.

Numa comparação imediata, notamos o evidente subdimensionamento do circuito exibidor brasileiro nas estatísticas do IBGE utilizadas por Takahashi. Segundo esses dados, entre 1947 e 1967 a média do número de cinemas no Brasil teria se mantido bem abaixo de 1.000 salas, variando entre 477 e 873 , números muito inferiores aos que apresentamos no Gráfico 1 (média de 1.430 salas).

Além disso, a partir de 1969, quando a fonte dos dados passa a ser o INC, os números também variam acentuadamente, dessa vez se elevando. Como é notório não ter havido qualquer acontecimento excepcional no mercado exibidor brasileiro entre 1967 e 1969 que justifique o enorme crescimento no número de cinemas informados em cada um desses anos - variando de 829 (segundo o IBGE) para 1.817 salas (segundo o INC), um aumento de mais de 100\% -, essa discrepância no espaço de dois anos é obviamente motivada por diferenças nas fontes originais dos dados. Uma mudança como a de 1967-1969 não se repete entre 1975-1976, quando há outra alteração na fonte dos dados, do INC para a Embrafilme, sendo possível perceber que a série do IBGE inegavelmente difere da série INC/Embrafilme ${ }^{7}$.

O problema estaria, então, nos dados do IBGE - originalmente publicados em seus Anuários Estatísticos do Brasil e atualmente disponibilizados na internet no site do $\mathrm{IBGE}^{8}$ - ou na leitura deles feita por Takahashi? Apesar de serem fontes promissoras para os historiadores do cinema brasileiro, os dados do IBGE devem ser descartados? Vamos examinar essa questão mais detalhadamente.

\footnotetext{
${ }^{6}$ Os dados de Takahashi (1985, p. 108) são idênticos aos fornecidos pela Ancine (BRASIL, 2017, p. 5) para o período entre 1971 e 1983, com exceção dos números referentes aos anos de 1982 (1.988 e 2.224 salas, respectivamente) e 1983 (1.736 e 1.938, respectivamente), que apresentam variações de aproximadamente 12\%. A origem dos dados da Ancine para esses dois anos é a Database Filme B de 2010. Mas esses mesmos dados referentes até o ano de 2002 já haviam sido publicados anteriormente por Almeida e Butcher (2003, p. 54). Porém, os dados referentes a 1995 são diferentes em duas pesquisas feitas pela mesma empresa (Filme B). Almeida e Butcher (2003) indicam 1.033 salas, enquanto Salem (1999, p. 255) anota 1.335 salas. É uma diferença importante, pois, no segundo caso, teríamos um crescimento constante entre 1993 e 1996, com uma queda acentuada em 1997.
}

${ }^{7}$ Cabe mencionar que a Embrafilme aos poucos incorporou parte das funções e da estrutura do INC, extinto pelo governo federal em 1975. Outras atribuições do INC, especialmente de regulação, seriam assumidas por um novo órgão, o Concine.

${ }^{8}$ Disponível em: <https://goo.gl/HthJg>. Acesso em: 25 out. 2017. 


\section{O IBGE e o imposto sobre salas de cinema}

No início da Nova República, o governo reconhecia que a tarefa de aquisição de informações primárias para a elaboração de estatísticas em um país de dimensões continentais como o Brasil era difícil e complexa. Havia duas alternativas: criar os dados através dos censos (caros e lentos), ou obtê-los através dos registros administrativos existentes em diferentes espaços e locais, sobretudo nos municípios (SENRA, 2008, p. 21).

Logo, reconheceu-se que era necessário criar uma estrutura de órgãos municipais de estatística, buscando integrá-los com as esferas estaduais e federal. Nesse processo, foi criado um órgão federal de estatística ligado diretamente ao Presidente da República, o Instituto Nacional de Estatística (INE), em 1934, posteriormente transformado no Instituto Brasileiro de Geografia e Estatística (IBGE), nome que vigora até os dias de hoje (SENRA, 2008, p. 25).

Para custear os órgãos municipais de estatística, um decreto federal criou, em 1942, a "quota de estatística”, delegando aos municípios a criação de um imposto de $10 \%$ do valor do ingresso das casas de diversões - incluindo os cinemas -, destinado ao IBGE e arrecadado através de um "selo de estatística” fornecido pelo próprio órgão federal. Esse imposto era uma taxa ou, no caso dos municípios que já possuíam impostos sobre diversões públicas, uma sobretaxa a incidir sobre as salas de cinema (SENRA, 2008, p. 31).

Apesar de alguns relatos sobre o rigor na cobrança do imposto sobre os cinemas pelos "agentes da estatística", podemos indagar se o IBGE quantificaria em suas estatísticas, particularmente nos primeiros anos, o número de cinemas contribuintes com o "selo de estatística" ou o número verdadeiro de salas que funcionavam, mas que sonegariam o imposto.

Além disso, é preciso verificar como a contabilização do número de salas de cinema em funcionamento no Brasil era incluída nas estatísticas do IBGE referentes às “casas de diversões públicas" existentes. Nas tabelas publicadas ao longo dos anos 1940 e 1950, o número total de casas era dividido em estabelecimentos "arrolados" ou "existentes"

\footnotetext{
${ }^{9}$ Humberto Pinto de Carvalho escreveu suas lembranças a respeito da cobrança do selo de estatística no Cine Itiúba, do interior da Bahia: "Para garantir a arrecadação e não haver sonegação o ingresso era impresso em papel de três cores diferentes [...]. No verso aplicação da data com carimbo do cinema. O selo era colado parte no canhoto e parte no bilhete. Ao ser destacado pela bilheteria do cinema era rompido esse elo. O pagante entregava o ingresso na entrada e o porteiro colocava na urna que, antecipadamente, havia sido lacrada pelo Agente da Estatística. No dia seguinte esse funcionário de carreira do IBGE abria a urna e contava os pedaços selados ali depositados. Conferia com o talonário dos canhotos e expedia uma nova guia para compra dos selos para uso futuro. Tudo em dinheiro. Não tinha choro nem vela”. Entretanto, o autor relata que havia uma resistência do exibidor à cobrança do imposto por este se destinar ao Tesouro Nacional - “chamado de saco-sem-fundo ou bolsa de viúva rica” -, e não ao município, além de configurar uma dor de cabeça e uma "sangria" dos escassos recursos dos pequenos cinemas do interior. Disponível em: <https://goo.gl/BiEooK>. Acesso em: 5 jun. 2017.
} 
e estabelecimentos "informantes", o que talvez diferenciasse os espaços mapeados diretamente pelos agentes do órgão federal daqueles espaços cujas informações eram coletadas por outros órgãos, quer municipais ou estaduais, e enviadas ao IBGE.

Entretanto, verificando as tabelas referentes às casas de diversões em diversos anos, a diferença entre o número de estabelecimentos informantes e arrolados nunca era tão significativa. No Anuário Estatístico do Brasil publicado em 1952 (INSTITUTO BRASILEIRO DE GEOGRAFIA E ESTATÍSTICA, 1952, p. 456), com dados referentes ao ano de 1949, por exemplo, eram indicadas 2.584 casas de diversões arroladas, sendo 2.399 casas informantes - uma diferença inferior a $10 \%$.

Mais problemático é o fato de que, nessas tabelas, as casas de diversões foram separadas ao longo dos anos em diferentes e diversas categorias, sobretudo teatro, cineteatros e cinemas. Assim, o IBGE não necessariamente classificava apenas como “cinemas" todos os espaços onde ocorriam exibições cinematográficas comerciais regulares, especialmente a partir de 1939, quando, além de "cineteatros", passaram a ser incluídas nas listagens de casas de diversões do Anuário Estatístico do Brasil categorias como "dancings", “cabarets”, “cassinos”, entre outras, que mantinham eventualmente projeções de filmes (INSTITUTO BRASILEIRO DE GEOGRAFIA E ESTATÍSTICA, 1946, p. 453).

Até o Anuário Estatístico do Brasil de 1957 (INSTITUTO BRASILEIRO DE GEOGRAFIA E ESTATÍSTICA, 1957, p. 416), o IBGE manteve separadas as categorias cinemas e cineteatros. Dali em diante, passou a contabilizar conjuntamente os dois tipos de estabelecimentos (apenas no anuário de 1967 os cineteatros e cinemas voltaram a ser inventariados separadamente). Portanto, na primeira metade dos anos 1950, as categorias utilizadas eram "teatros", "cineteatros", "cinemas" e "outros", enquanto na década de 1960 as casas de diversões passaram a ser divididas somente entre "teatro" e "cineteatros e cinemas".

Diante dessas questões, percebemos que Takahashi incluiu em seu quadro apenas o número de "cinemas" informados pelo IBGE, ignorando outras categorias, principalmente os "cineteatros". Isso é sumamente problemático, pois ao longo de vários anos o número de cineteatros em funcionamento no Brasil era muito superior ao de cinemas. No Anuário Estatístico do Brasil de 1952 (INSTITUTO BRASILEIRO DE GEOGRAFIA E ESTATÍSTICA, 1952, p. 456), referente ao ano de 1949, por exemplo, são listados 1.555 cineteatros contra apenas 729 cinemas, menos da metade daqueles. Já no Anuário Estatístico do Brasil de 1957 (INSTITUTO BRASILEIRO DE GEOGRAFIA E ESTATÍSTICA, 1957, p. 416), com dados do ano de 1955, a situação tinha se invertido: o número de cinemas (2.114) representava o dobro do número de cineteatros (1.024). 
Essa seria a razão do aparente subdimensionamento do circuito exibidor brasileiro nas estatísticas do IBGE quando comparadas com os dados do INC e da Embrafilme no artigo de Takahashi. Mas qual seria a opção correta para ler e interpretar os dados do IBGE?

\section{Dados do IBGE a partir de outras fontes}

Outra dificuldade em relação à utilização dos dados do IBGE para quantificar o número de cinemas existentes no Brasil entre as décadas de 1940 e 1970 também se deve ao fato de encontrarmos, em outras fontes, números diferentes dos citados por Takahashi, alguns deles igualmente creditados ao órgão federal, no entanto. Os dados apresentados por três publicações, de autoria de Alberto Victor de Magalhães Fonseca (1955), Francisco Silva Nobre (1957) e Geraldo Santos Pereira (1973), e por artigos em dois periódicos - Revista Geicine (1961) e Filme Cultura (1967) - serão comparados.

Alberto Victor de Magalhães Fonseca, funcionário do Banco do Brasil, foi o autor de uma brochura intitulada Preços de ingressos, na presente conjuntura do país, que consistia no parecer elaborado e lido por ele no plenário da Comissão Federal de Abastecimento e Preços (Cofap), em 30 de novembro de 1955. Em seu parecer, Fonseca elaborou um quadro com o número de salas de cinema no Brasil a partir de dados do IBGE.

Nascido em 1923, o escritor e jornalista cearense Francisco Silva Nobre ingressou por concurso público no Banco do Brasil em 1944, seguindo carreira no setor bancário. Amante e pesquisador da sétima arte, seu segundo livro, Mercado de cinema no Brasil, publicado em 1957, foi provavelmente o primeiro estudo dedicado à exibição cinematográfica em nosso país. Nesse livro o autor traz quadros com o número de salas de cinema brasileiras cujas informações, assim como em Fonseca, são creditadas ao IBGE.

Geraldo Santos Pereira foi cineasta e gestor público mineiro, tendo atuado em comissões e órgãos federais ligados ao cinema entre as décadas de 1950 e 1960, como o Conselho Federal de Cinema, o Grupo Executivo da Indústria Cinematográfica e o INC. Em 1973, lançou o livro Plano geral do cinema brasileiro: história, cultura, economia e legislação, no qual traz alguns números do circuito exibidor brasileiro, sem indicar a fonte no qual se baseou.

As duas últimas fontes são revistas publicadas por órgãos oficiais. A primeira é a Revista Geicine, que em seu primeiro número, de 1961, traz dados creditados ao Serviço de Estatística do Ministério da Educação e Cultura (MEC). A segunda é a revista Filme Cultura, publicada pelo INC, que na sua quarta edição, de 1967, apresenta números retirados do anuário estatístico do IBGE. 


\begin{tabular}{|c|c|c|c|c|c|c|c|c|}
\hline Ano & Nobre & Fonseca & Pereira & $\begin{array}{l}\text { Filme } \\
\text { Cultura }\end{array}$ & $\begin{array}{l}\text { Revista } \\
\text { Geicine }\end{array}$ & $\begin{array}{c}\text { IBGE } \\
\text { Arrolados }\end{array}$ & $\begin{array}{l}\text { IBGE: soma } \\
\text { "cinema"e } \\
\text { "cineteatro" }\end{array}$ & $\begin{array}{c}\text { IBGE: } \\
\text { "Cinema e } \\
\text { cineteatro" }\end{array}$ \\
\hline 1944 & & & & & & 1666 & 1317 & $\begin{array}{l}947 \\
370 \\
\end{array}$ \\
\hline \multicolumn{9}{|l|}{1945} \\
\hline 1946 & 1606 & & 1606 & & & 1811 & 1606 & $\begin{array}{c}427 \\
1179 \\
\end{array}$ \\
\hline 1947 & 1736 & & & & & 1969 & 1736 & $\begin{array}{c}466 \\
1270 \\
\end{array}$ \\
\hline 1948 & 1973 & 1973 & & & & & 1973 & $\begin{array}{c}588 \\
1385\end{array}$ \\
\hline 1949 & 2248 & 2284 & 2248 & & & 2584 & 2284 & $\begin{array}{c}729 \\
1555 \\
\end{array}$ \\
\hline 1950 & 2656 & 2411 & & & & 3011 & 2656 & $\begin{array}{c}927 \\
1729 \\
\end{array}$ \\
\hline 1951 & 3033 & & 3033 & & & 3467 & 3033 & $\begin{array}{l}1149 \\
1884\end{array}$ \\
\hline \multicolumn{9}{|l|}{1952} \\
\hline 1953 & 2857 & 3216 & 2857 & & & 2591 & 2857 & \\
\hline 1954 & 2953 & & & & & & 2953 & $\begin{array}{l}1159 \\
1794 \\
\end{array}$ \\
\hline 1955 & & & 3017 & & & 3301 & 3138 & $\begin{array}{l}2114 \\
1024 \\
\end{array}$ \\
\hline \multicolumn{9}{|l|}{1956} \\
\hline 1957 & & & & & & & 3303 & \\
\hline 1958 & & & & 3413 & & & 3413 & \\
\hline 1959 & & & 3318 & 3489 & 3704 & & 3488 & \\
\hline 1960 & & & & 3285 & & & 3284 & \\
\hline 1961 & & & & 3242 & & 3242 & 3242 & \\
\hline 1962 & & & & & & 3169 & 3169 & \\
\hline 1963 & & & & 3261 & & 3261 & 3261 & \\
\hline 1964 & & & 3117 & & & 3234 & 3234 & \\
\hline \multicolumn{9}{|l|}{1965} \\
\hline \multicolumn{9}{|l|}{1966} \\
\hline 1967 & & & & & & 3079 & 3196 & $\begin{array}{c}3079 \\
117\end{array}$ \\
\hline 1968 & & & & & & & & \\
\hline
\end{tabular}

Tabela 1: Número de salas de cinema e cineteatros no Brasil (1944-1967)

Fonte: Elaborado pelos autores (2017), com base em Fonseca (1955), Nobre (1957), Pereira (1973), Filme Cultura (1967), Revista Geicine (1961) e Instituto Brasileiro de Geografia e Estatística (1946, 1949, 1950, 1951, 1952, 1953a, 1953b, 1954, 1955, 1957, 1959, 1960, 1961, 1962, 1963, 1965, 1966, 1969). 
Na Tabela 1 reunimos, além dos dados contidos nos anuários estatísticos do IBGE, as informações sobre o número de salas que constam em todos os autores e revistas citados. É importante ressaltar que no caso dos anuários, no entanto, os relatórios elaborados em determinado ano, geralmente mencionado no título, referem-se a dados coletados em outro período, com dois ou três anos de diferença. São destacados em negrito ou itálico os números que se repetem em mais de uma fonte.

Percebemos, portanto, que Nobre, Fonseca e Pereira, sem mencionar essa questão, em geral elaboraram seus quadros e tabelas com o número de salas de cinema do Brasil somando os dados apresentados separadamente pelo IBGE de cinemas e cineteatros. A Filme Cultura fez o mesmo, mas explicitando se tratar do "número de cinemas e cineteatros". A opção tem coerência, é claro, uma vez que, sobretudo nas cidades do interior do Brasil, a maior parte das salas de diversões funcionavam regularmente exibindo filmes e recebendo peças teatrais, shows e diversos outros tipos de atrações de palco.

Dessa maneira, podemos considerar erros os números que destoam muito ligeiramente, como no ano de 1959, em que a Filme Cultura indica 2.489 salas, enquanto para o IBGE seriam 2.488; assim como em 1960, quando essa revista indica 3.285, e o órgão federal aponta 3.284. Números invertidos também parecem indicar erros, como no ano de 1949, em que o IBGE e Fonseca citam 2.284, enquanto Nobre e Pereira anotam 2.248. Entretanto, não há explicação clara sobre divergências mais acentuadas, por exemplo, entre Nobre ou o IBGE e Fonseca, em 1950, tendo os primeiros indicado 2.656 e o segundo, 2.411. Casos assim se repetem em 1953, 1955, 1959 e 1964.

Apesar de todas as divergências, utilizando os dados da Tabela 1, temos um resultado no Gráfico 3 que demonstra mais coerência do que o apresentado por Takahashi. 


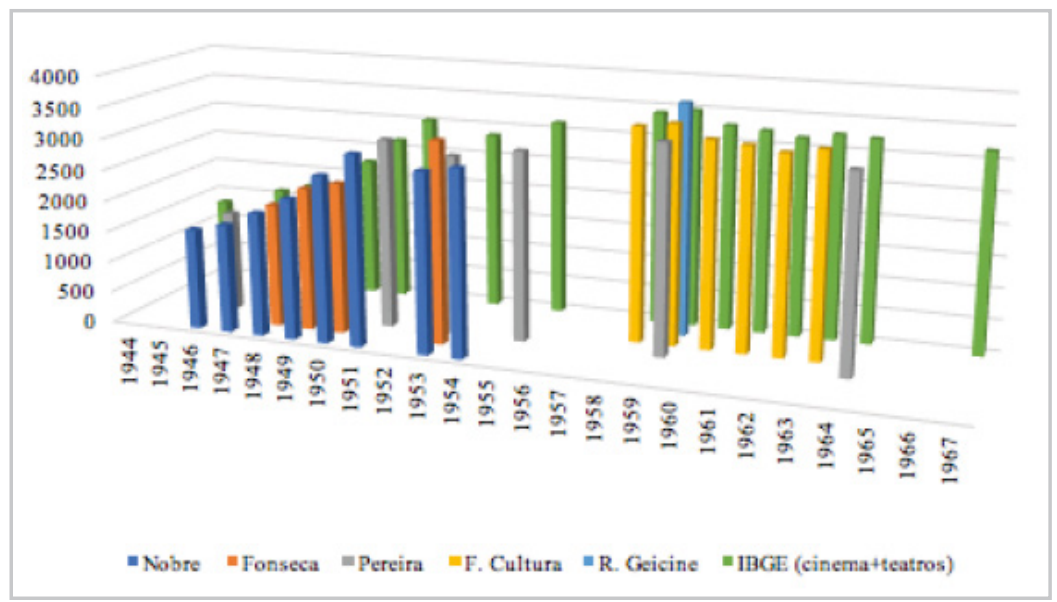

Gráfico 3: Evolução do número de salas de cinema do Brasil (1944-1969).

Fonte: Elaborado pelos autores (2017), com base em Fonseca (1955), Nobre (1957), Pereira (1973), Filme Cultura (1967), Revista Geicine (1961) e Instituto Brasileiro de Geografia e Estatística (1946, 1949, 1950, 1951, 1952, 1953a, 1953b, 1954, 1955, 1957, 1959, 1960, 1961, 1962, 1963, 1965, 1966, 1969).

Por fim, priorizando os dados do IBGE (a soma do número de cinemas e cineteatros) para o período 1944 a 1967, teríamos um resultado mais claro e confiável expresso no Gráfico 4:

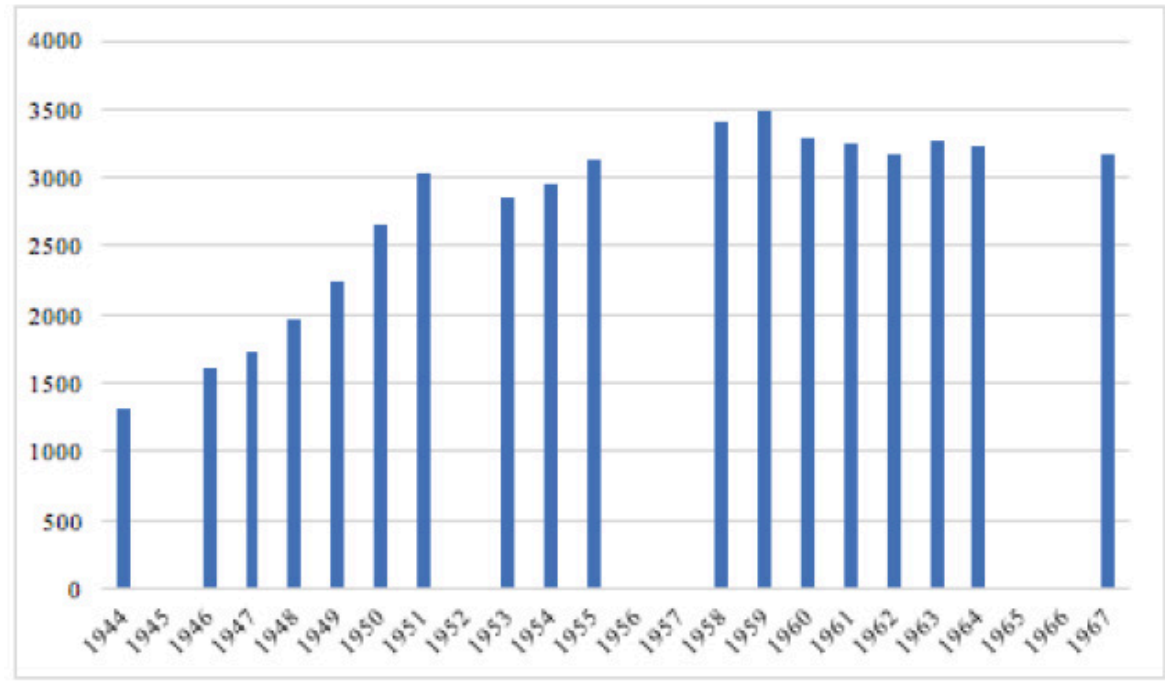

4: Evolução do número de salas de cinema do Brasil (1944-1967).

Fonte: Elaborado pelos autores (2017), com base em Instituto Brasileiro de Geografia e Estatística $(1946,1949,1950,1951,1952,1953 \mathrm{a}, 1953 \mathrm{~b}, 1954,1955,1957,1959,1960,1961,1962$, 1963, 1965, 1966, 1969). 
Diferentemente do que apresentou Takahashi (Gráfico 2), no Gráfico 4 o número médio de salas (2.765) entre 1944 e 1967 é superior ao da década de 1930 (Gráfico 1), revelando também uma continuidade mais coerente entre os dados apresentados para esses dois períodos: de 1.350 salas em 1939, passamos para 1.317 em 1944. Diante desses números, aparentemente mais confiáveis, podemos indicar a manutenção do tamanho do circuito exibidor brasileiro ao longo da Segunda Guerra Mundial (1939-1945), com um crescimento contínuo e acelerado após o fim do conflito, na segunda metade da década de 1940. Continuando mais lentamente essa ampliação, o circuito atingiria seu ápice no final dos anos 1950.

Esclarecido esse período, passemos agora à comparação dos dados do Gráfico 4 com a série INC/Embrafilme a partir de 1969.

\section{Queda ou crescimento nos anos Embrafilme?}

1969 foi o ano de criação da Embrafilme e foi também quando o INC passou a coletar e a divulgar sistematicamente números relativos ao tamanho do circuito exibidor. No Gráfico 5, juntamos a série 1944-1967, do Gráfico 4, com a série 1969-1982, do Gráfico 2, obtendo-se:

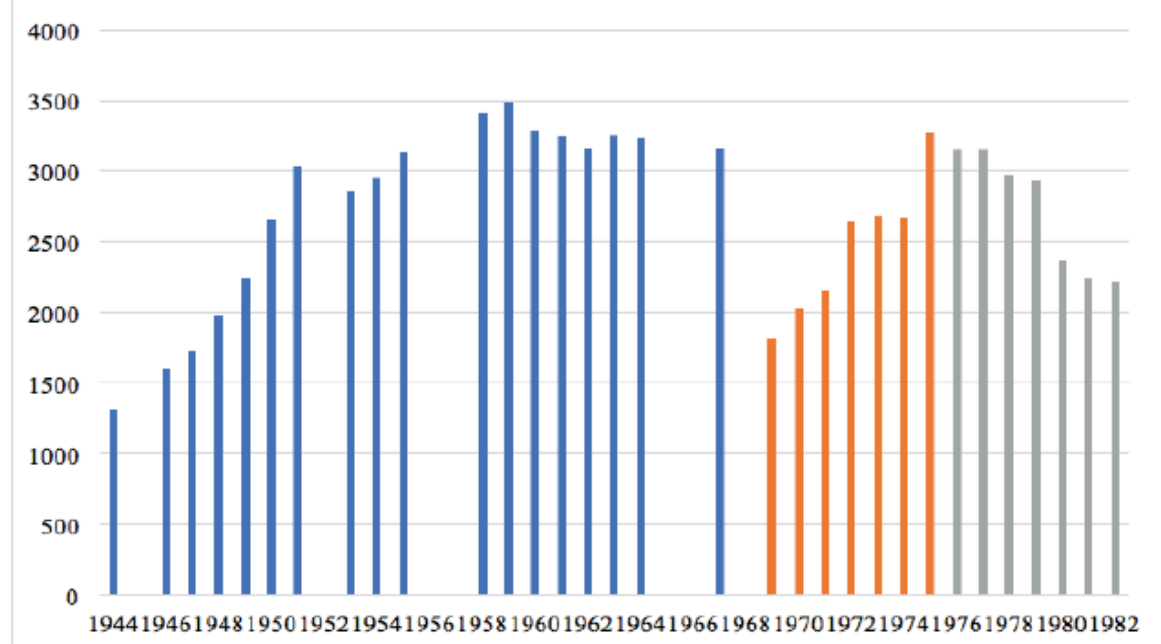

Gráfico 5: Evolução do número de salas de cinema do Brasil (1944-1982).

Fonte: Elaborado pelos autores (2017), com base em Instituto Brasileiro de Geografia e Estatística $(1946,1949,1950,1951,1952,1953 \mathrm{a}, 1953 \mathrm{~b}, 1954,1955,1957,1959,1960,1961,1962$, 1963, 1965, 1966, 1969) e Takahashi (1985). 
Em comparação com o Gráfico 2, ao invés de crescimento, temos no Gráfico 5 uma queda acentuada do número de salas entre 1967 e 1969. Podemos sugerir que essa diferença (de 3.117 para 1.817, queda de 58\% em dois anos) também possa ser fruto de diferentes metodologias no levantamento desses dados, uns oriundos do IBGE, outros do INC. Mas, por outro lado, atentando para a crise econômica da segunda metade dos anos 1960, responsável, por exemplo, pela falência e concordata de inúmeras empresas no Rio de Janeiro (GONZAGA, 1996), talvez seja mais correto considerar a existência de uma queda do que de um crescimento do circuito exibidor brasileiro nos últimos anos da década de 1960.

Entretanto, o Gráfico 5 difere ligeiramente do recentemente apresentado por Anita Simis (2015, p. 685). A autora utilizou para um largo período, inclusive 1970-1985, não os dados do INC/Embrafilme, mas apenas os dos anuários estatísticos do IBGE. Apesar do menor número de informações - ela apresenta valores apenas para os anos de 1971, 1974, 1980, 1981, 1984 e 1985 -, seu gráfico apresenta uma variação menos intensa no número de salas de cinema entre as décadas de 1960 e 1970, sempre próximo de 3 mil. Essa alternativa pode ser comparada no Gráfico $6^{10}$.

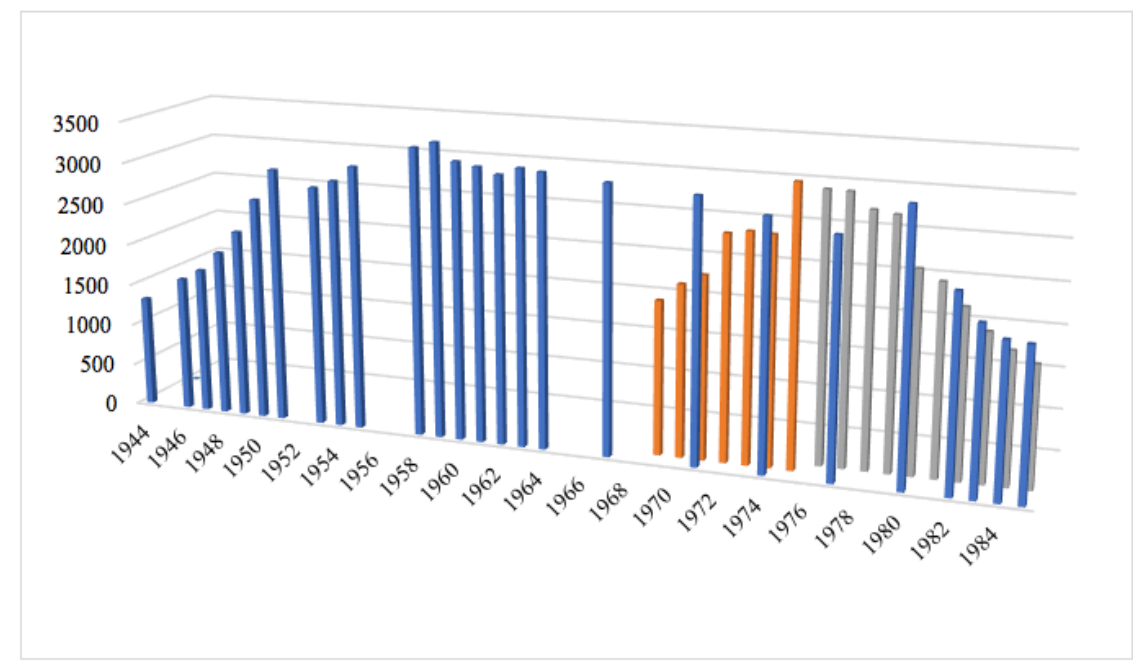

Gráfico 6: Evolução do número de salas de cinema do Brasil (1944-1982).

Fonte: Elaborado pelos autores (2017), com base em Instituto Brasileiro de Geografia e Estatística $(1946,1949$, 1950, 1951, 1952, 1953a, 1953b, 1954, 1955, 1957, 1959, 1960, 1961, 1962, 1963, 1965, 1966, 1969, 1974, 1976, 1979, 1983, 1984, 1985, 1986, 1988) e Takahashi (1985).

\footnotetext{
${ }^{10} \mathrm{~A}$ partir de uma pesquisa diretamente nos anuários estatísticos do IBGE (INSTITUTO BRASILEIRO DE GEOGRAFIA E ESTATÍSTICA, 1974, 1976, 1979, 1983, 1984, 1985, 1986, 1988) disponíveis online, obtivemos informações sobre anos que não constam no gráfico exposto por Simis (2015). Apesar de os dados referentes a 1981 e 1986 não haverem sido encontrados, os dos anos 1977, 1982 e 1983 foram acessados e analisados.
} 
No Gráfico 6, se considerarmos os dados do INC/Embrafilme (em laranja e cinza), perceberemos uma queda brusca no final dos anos 1960, um crescimento ao longo do início da década de 1970 (atingindo o ápice em 1975) e uma lenta queda que se acentua significativamente entre 1979 e 1980 - uma diminuição de quase $20 \%$ do circuito de um ano para o outro.

Já se considerarmos os dados do IBGE (em azul) para o período de 1969 a 1985 - como feito por Simis (2015) -, o quadro seria outro. Veríamos uma ligeira, mas contínua diminuição do número de salas de cinema a partir de meados da década de 1960 até fins da década de 1970. Isto é, uma lenta queda do circuito, de 13\% ao longo de treze anos, entre 1964 a 1977. Após uma recuperação em 1980, haveria uma queda mais brusca em 1982.

Portanto, o Gráfico 6 nos traz a dúvida sobre se houve uma retomada do crescimento do circuito exibidor em meados da década de 1970, após a queda no final dos anos 1960, ou se o que ocorreu foi uma gradual e contínua diminuição do número de salas de cinema entre as décadas de 1960 e 1980.

Embora atualmente os pesquisadores usem os dados do INC/Embrafilme para os anos 1970 sem nenhum questionamento, uma das primeiras pesquisas realizadas pela Filme B para a Secretaria do Audiovisual fazia uma importante ressalva sobre essas informações:

A grande variação do número de salas entre 1974 e 1975 pode ser atribuída à campanha de recadastramento do Concine, bem como por este cadastramento ter considerado as salas $16 \mathrm{~mm}$, cinemas $180^{\circ}$, clubes etc. O fechamento desse tipo de sala, entre 1976/81, deve ter influído na brusca queda de 1979 para 1980/1981 (SALEM, 1999, p. 253).

Essa observação talvez nos leve a referendar a queda lenta e contínua do circuito ao longo dos anos 1970 apontada pelos dados do IBGE.

Mas o que nossas considerações sobre os gráficos até agora apresentados atestam, com mais segurança, é o crescimento do circuito exibidor brasileiro de meados da década de 1940 até fins dos anos 1950, quando o número de salas de cinema no Brasil atingiu o seu ponto máximo. Ou seja, identificamos o apogeu do circuito exibidor em meados do século XX, após o inegável desenvolvimento no pósguerra, quando parece ter ocorrido a superação definitiva da crise do setor de exibição provocada pela introdução do cinema sonoro. Embora, como vimos, permaneçam incertezas sobre as variações do número de salas de exibição entre as décadas de 1960 e 1970, é inegável a crise na primeira metade dos anos 1980, quando o tamanho do circuito retornou aos mesmos patamares da década de 1930. 
Entretanto, como vemos no Gráfico 7 (priorizando os dados do IBGE), a partir dos anos 2000 o Brasil presenciou uma retomada no crescimento de seu circuito exibidor, revelando um aumento praticamente contínuo até a presente data, retornando aos patamares dos anos 1950. Mas é importante lembrar que a comparação do número de salas de cinema na atualidade com o de décadas passadas deve levar em conta outros aspectos da história do circuito exibidor brasileiro, como as transformações na dimensão da sala de exibição.

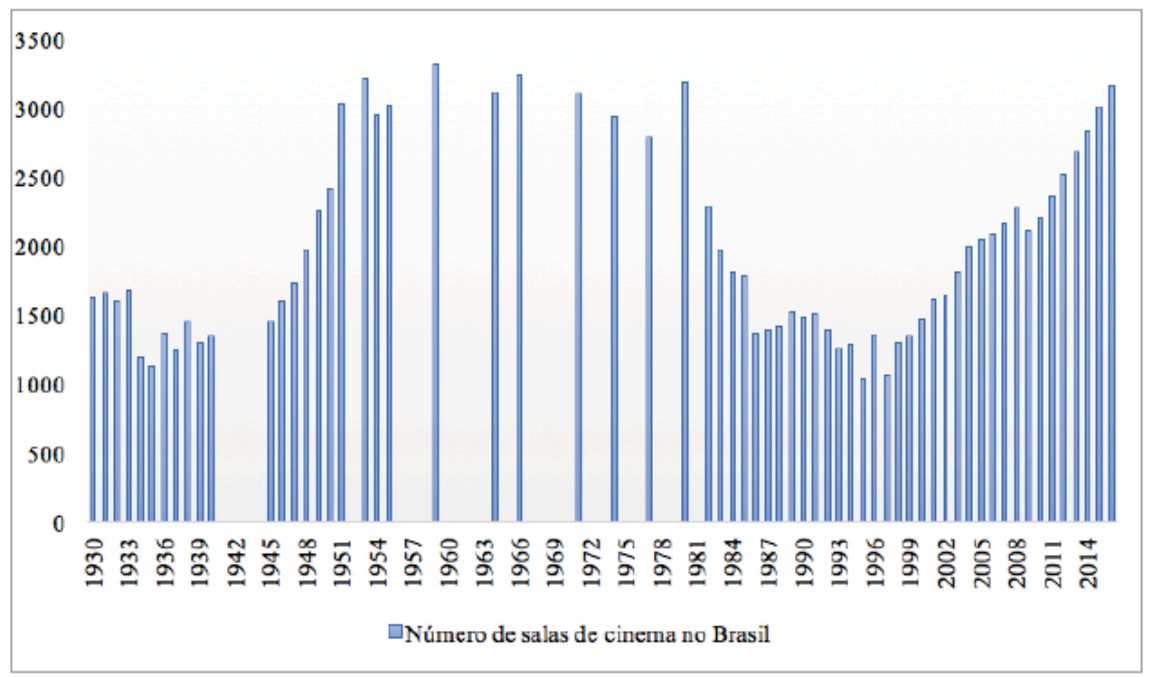

Gráfico 7: Evolução das salas de cinema no Brasil (1930-2012).

Fonte: Elaborado pelos autores (2017), com base em Souza e Freire (2017) e Instituto Brasileiro de Geografia e Estatística (1946, 1949, 1950, 1951, 1952, 1953a, 1953b, 1954, 1955, 1957 , 1959, 1960, 1961, 1962, 1963, 1965, 1966, 1969, 1974, 1976, 1979, 1983, 1984, 1985, 1986, $1988,2017)$.

\section{A questão do número de poltronas nas salas de cinema}

Além das imprecisões e divergências em relação aos dados obtidos de diferentes fontes, é preciso reconhecer que estatísticas baseadas apenas no número de salas de cinema existentes no Brasil possuem claras limitações para a análise do mercado exibidor. Para estimar a dimensão do público espectador brasileiro e refletir sobre a importância do cinema como atividade social e econômica, por exemplo, é fundamental levar em conta a lotação das salas de exibição, atentando para tendências históricas de diminuição ou ampliação do tamanho dos cinemas e de seu público. 
O surgimento dos primeiros palácios cinematográficos em cidades como São Paulo ou Rio de Janeiro nos anos 1920 era evidência de um vigoroso desenvolvimento do mercado. Em meados dessa década, um comentário na revista carioca Selecta anunciava: “já se foi o tempo que o Rio tinha as suas salinhas de duzentos lugares" (SELECTA, 1925). Naquele momento, o crítico comentava as ampliações dos cinemas da rua da Carioca (os cines Iris e Ideal), assim como o melhoramento nas salas de bairro - como o cine Atlântico, em Copacabana, e o cine Guanabara, em Botafogo -, que ultrapassavam as mil poltronas. O comentário de Selecta (1925) tinha em vista ainda a iminente abertura dos primeiros palácios de cinema nos arranha-céus na região do centro, posteriormente conhecido como Cinelândia, a partir daquele mesmo ano.

Algo semelhante ocorreu em São Paulo, ainda que sem a suntuosidade dos movie palaces cariocas. Em seu recente estudo sobre os cinemas de São Paulo, José Inácio de Melo Souza destacou o ciclo de construções iniciado em 1921, destacando “a lógica de agigantamento dos espaços cinematográficos" em curso na capital paulistana (SOUZA, 2016, p. 229, 236).

Com o advento do filme sonoro e com a necessidade de investimentos financeiros mais vultosos para a construção de salas modernas e para sua atualização tecnológica, ocorreu ainda maior incentivo à criação de cinemas mais amplos, com lotações próximas ou até superiores a dois mil lugares. Mas se essa tendência seria reforçada sobretudo no pós-guerra, já na década de 1930 as salas de cinema construídas especialmente para esse fim apresentariam uma lotação mediana superior àquela usual nos antigos salões adaptados para a projeção de filmes.

Segundo um trecho do relatório do Departamento de Comércio norteamericano reproduzido pela revista Business Screen Magazine (TECHNICAL..., 1940, p. 28), o Brasil possuía 1.300 salas, totalizando 750 mil lugares em 1940, o que indicaria uma lotação média das salas brasileiras de 576 assentos. Nas estatísticas do IBGE referentes a 1937, quantificava-se em 625.600 a capacidade total dos 1.214 “teatros, salões e cinemas" existentes, resultando numa capacidade média semelhante de 515 lugares por estabelecimento (INSTITUTO BRASILEIRO DE GEOGRAFIA E ESTATÍSTICA, 1941, p. 1142).

Embora tradicionalmente houvesse uma marcada diferença entre os grandes cinemas das capitais e os mais acanhados cinemas do interior, o tamanho médio das salas se manteria nas décadas seguintes. Em meados dos anos 1950, os cinemas brasileiros ainda possuíam em média 532 lugares. As capitais eram responsáveis por $20 \%$ dos cinemas do país e suas salas eram maiores, com cerca de 801 lugares, 
em média. A maior parte do circuito, porém, ficava no interior, onde os cinemas possuíam em média 464 assentos (NOBRE, 1957, p. 19).

A partir dos anos 1970, porém, seria cada vez mais frequente que antigos e grandes cinemas fossem divididos em duas ou três salas. Já os novos cinemas teriam capacidades mais reduzidas, com o surgimento de salas de exibição em galerias comerciais e, posteriormente, em shopping centers, quase sempre de lotação inferior a 400 lugares.

A diminuição radical e definitiva viria especialmente a partir do final dos anos 1990, com a proliferação dos multiplexes invariavelmente instalados em shopping centers, que consistem em complexos de salas pequenas, com 200 ou 300 poltronas, em média. Essa reformulação do circuito exibidor obrigou a efetiva distinção entre salas (ou telas) e cinemas, já que se tornou cada vez mais comum, até se estabelecer como padrão atual do mercado, que um cinema tivesse mais de uma sala de exibição.

Uma opção metodológica importante é tentar aliar diagnósticos nacionais com estudos locais mais detalhados. Para discutir a tendência histórica de diminuição do tamanho das salas de cinema brasileiras, o circuito exibidor da cidade de Niterói pode servir novamente de exemplo. Embora não deva necessariamente espelhar a realidade de outras localidades, Niterói apresenta uma trajetória que certamente se reproduziu em outras cidades com características demográficas e socioeconômicas semelhantes.

Em 1940, a cidade de Niterói possuía 8 cinemas e cineteatros em funcionamento, totalizando 8.570 lugares, ou seja, uma média de 1.071 poltronas por estabelecimento (FORTE, 1941, p. 285-286). Na década de 1950, a então capital do Estado do Rio de Janeiro chegou a ter 15 cinemas que comportavam 14.172 espectadores, isto é, 944 por sala (NOBRE, 1957, p. 19). Em meados dos anos 1970, o circuito niteroiense diminuiu para 11 cinemas, contendo 10.800 poltronas e uma lotação média de 980 lugares (FREIRE, 2012, p. 204-205).

Uma queda muito mais acentuada seria notada em 1983: o número de poltronas em Niterói cairia para menos da metade, 4.986 poltronas. A cidade tinha então 8 cinemas, com uma média de 623 assentos por sala (EMPRESA BRASILEIRA DE FILMES, 1983, p. 32).

Já no início dos anos 1990, após o fechamento de mais cinemas de rua, mas agora contando com cinemas no interior do Niterói Shopping e do Plaza Shopping, Niterói passava a ter 11 telas, responsáveis por 5.700 lugares. A lotação média de 580 lugares representava apenas uma pequena diminuição (FREIRE, 2012, p. 218-229).

Em 2012, a cidade continuava possuindo 11 telas, mas agora elas eram distribuídas em apenas dois multiplexes (no Plaza Shopping e no Shopping Bay Market). Esses dois espaços totalizavam somente 2.416 lugares, resultando numa 
lotação média de apenas 219 lugares, menos da metade do que existia nos cinemas da cidade vinte anos antes (FREIRE, 2012, p. 230-236).

Em 2017, o número de telas encontra-se num patamar superior devido à reabertura do Cine Arte UFF (pertencente à Universidade Federal Fluminense), em 2014, e à inauguração do complexo de cinco salas da Reserva Cultural, em São Domingos, em 2016. Niterói agora conta com 18 telas, totalizando um número mais elevado, de 3.687 lugares. A lotação média diminuiu ainda mais, para 204 lugares, mostrando que o recente crescimento do circuito se baseia no padrão de salas cada vez menores, como a sala 4 da Reserva Cultural, com apenas 82 assentos.

No Gráfico 8, vemos que o número de salas/telas em Niterói voltou a crescer nos últimos anos: hoje a cidade conta com o maior circuito de toda a sua história.

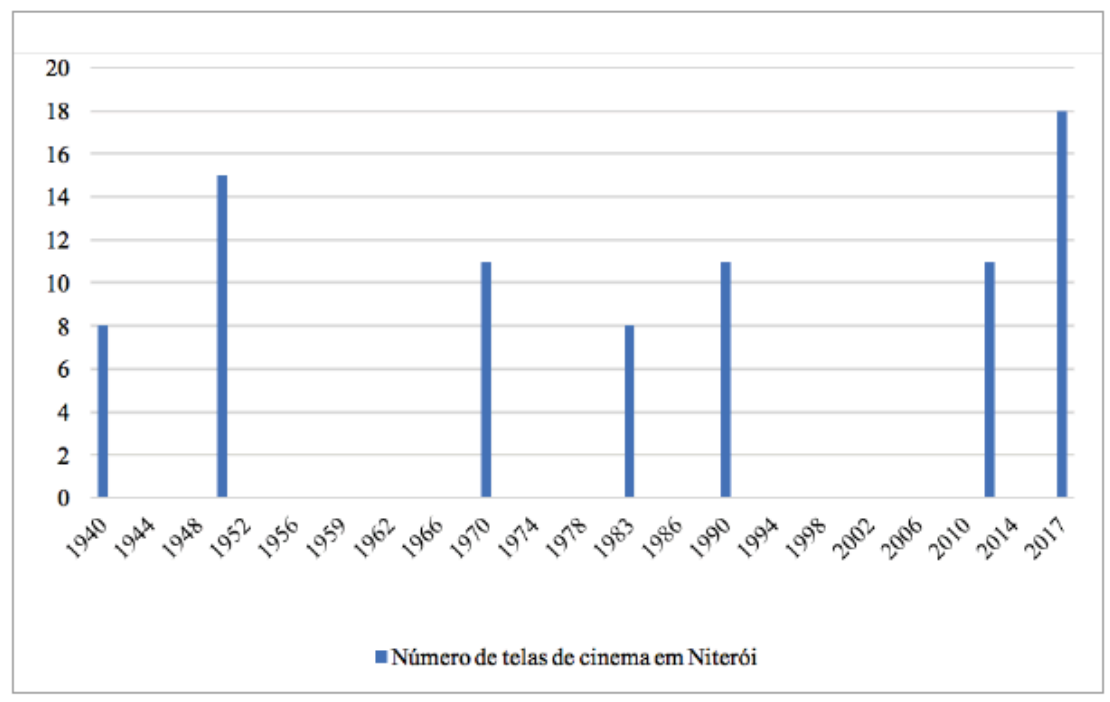

Gráfico 8: Número de telas em Niterói (1940-2017).

Fonte: Elaborado pelos autores (2017), com base em Forte (1941), Nobre (1957), Empresa Brasileira de Filmes (1983) e Freire (2012).

Entretanto, analisando o circuito exibidor niteroiense do ponto de vista da oferta de assentos, vemos um quadro bem diferente. No Gráfico 9, percebemos uma queda praticamente contínua no número de poltronas de cinema na cidade dos anos 1950 até a atualidade, com pequenas recuperações em 1990 e em 2017. 


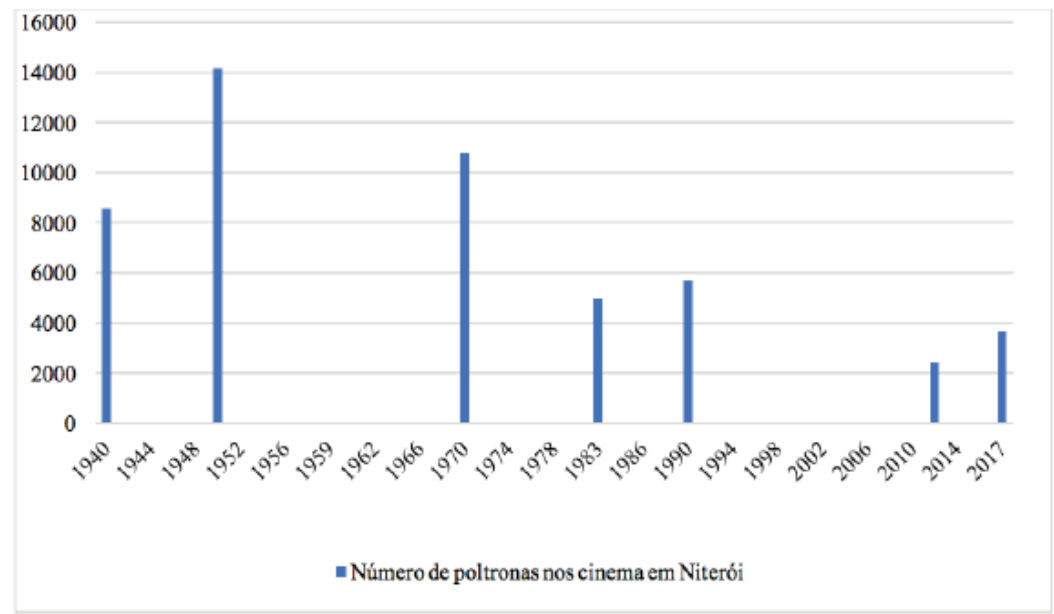

Gráfico 9: Número de poltronas de cinema de Niterói (1940-2017).

Fonte: Elaborado pelos autores (2017), com base em Forte (1941), Nobre (1957), Empresa Brasileira de Filmes (1983) e Freire (2012).

Analisando, no Gráfico 10, o tipo de sala de cinema existente em Niterói em relação à sua lotação máxima, temos um resultado novamente diferente. O que percebemos é uma queda absolutamente contínua do tamanho dos espaços de exibição dos anos 1970 em diante, tendo como auge a década de 1940, e não a de 1950.

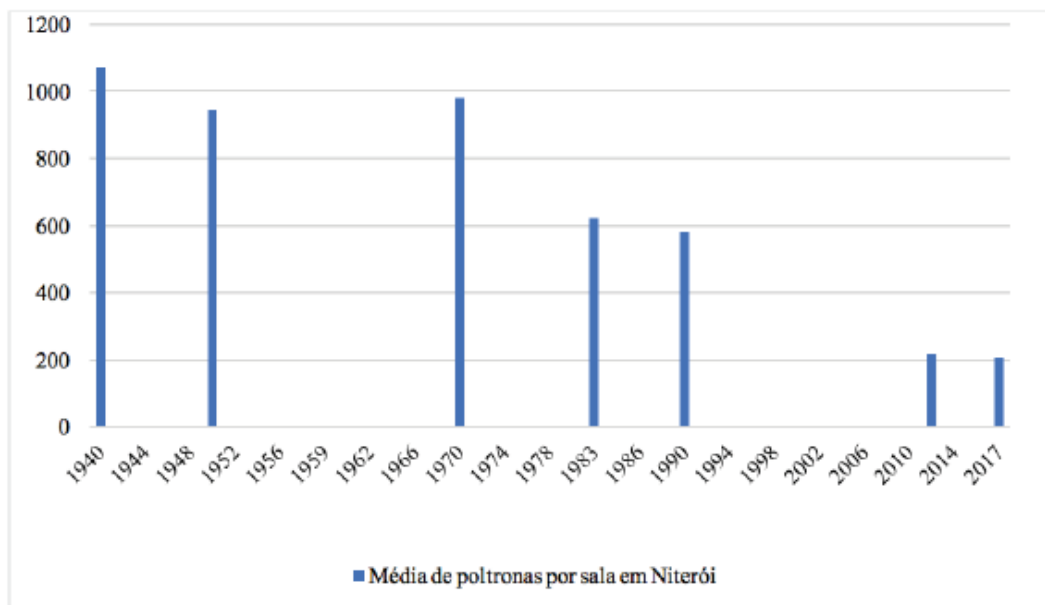

Gráfico 10: Média de poltronas por sala em Niterói (1940-2017).

Fonte: Elaborado pelos autores (2017), com base em Forte (1941), Nobre (1957), Empresa Brasileira de Filmes (1983) e Freire (2012). 
Portanto, vem ocorrendo a imposição de um modelo de salas cada vez menores, hoje com cerca de duzentos lugares. Novamente ocorreu uma queda muito acentuada na segunda metade dos anos 1970 (com o surgimento dos cinemas de galeria na cidade), mas com uma segunda diminuição igualmente intensa na passagem para os anos 2000, diante da afirmação do modelo dos multiplexes em Niterói.

Assim, tomando a cidade como exemplo, os gráficos 9 e 10 trazem novas variações e muito mais complexidade para a compreensão do mercado exibidor, para além da variação no tamanho do circuito (Gráfico 8). Se Niterói hoje conta provavelmente com a maior oferta de filmes em cartaz simultaneamente nas telas de cinema da cidade em toda a sua história, temos um público provavelmente menor do que nos anos 1980 e 1990 vendo filmes em salas que nunca foram tão pequenas.

\section{Conclusão}

Ao analisarmos as variações no número de salas de exibição cinematográfica no Brasil ao longo de grande parte do século XX, identificamos a imprecisão e a discrepância dos dados das diferentes fontes disponíveis para consulta. Com o agrupamento das informações acessadas, foi possível detectar a complementaridade de certos materiais e, ao mesmo tempo, o conflito entre outros dados. Assim, nos propusemos a questionar e averiguar o contexto em que essas informações foram produzidas, bem como sua validade e semelhança com dados apresentados por fontes diversas.

Os anuários estatísticos do IBGE se revelaram materiais de consulta essenciais para diversos autores que abordaram o circuito exibidor brasileiro em suas obras. No entanto, mesmo com a origem comum dos dados, foram encontradas divergências entre os números de salas indicados por eles. Notamos, então, que em muitos casos foram utilizadas as informações referentes à soma da quantidade de cinemas e cineteatros, enquanto em outros foram levados em consideração somente os números relacionados aos cinemas. Mesmo pressupondo que cinemas e cineteatros se complementam, sentimos falta de atenção a demais espaços que poderiam manter projeções regulares, e que possivelmente estavam contidos na categoria "outros", presente nos anuários.

Do ponto de vista da variação do número de salas de exibição no circuito exibidor brasileiro, apesar de algumas divergências, temos condições de afirmar que houve uma acentuada diminuição entre 1933 e 1935, justificada pelas dificuldades dos exibidores com a chegada do cinema sonoro. Na segunda metade da década da 1930, pudemos notar um princípio de estabilidade no circuito, porém com uma quantidade de salas ainda menor do que a encontrada no início da década. Após 
o término da Segunda Guerra Mundial (1939-1945), apontamos uma expansão constante e acelerada no setor, até atingir seu ápice no final dos anos 1950. Mesmo que ainda se mantenham algumas dúvidas sobre as mudanças no número de salas de exibição existentes ao longo das décadas de 1960 e 1970, a crise na primeira metade dos anos 1980 é inquestionável, já que, como visto anteriormente, a dimensão do circuito retornou aos mesmos parâmetros da década de 1930. Já nos anos 2000, acompanhamos novamente um crescimento da quantidade de salas de exibição no Brasil, que se mostra constante até o presente momento.

Por fim, destacamos a importância de aliar diagnósticos nacionais com estudos locais mais aprofundados. Utilizando o exemplo da cidade de Niterói, mostramos como variáveis, tais como mudanças históricas no número de poltronas e o tamanho médio das salas, trazem nuances reveladoras para análise do circuito exibidor cinematográfico.

\section{Referências}

ALMEIDA, P. S.; BUTCHER, P. Cinema, desenvolvimento e mercado. Rio de Janeiro: Aeroplano, 2003.

ALVETTI, C. R. P. O cinema brasileiro na crônica paranaense dos anos trinta. 1989. Dissertação (Mestrado) - Universidade de São Paulo, São Paulo, 1989.

BRASIL. Agência Nacional do Cinema. Segmento de Salas de Exibição: informe anual 2016-01 de janeiro a 31 de dezembro. Brasília, DF, 2017. Disponível em: $<$ https://goo.gl/old7DE>. Acesso em: 24 out. 2017.

EMPRESA BRASILEIRA DE FILMES. Cadastro de cinemas. Rio de Janeiro, 1983. Mimeografado.

CARVALHO, F. P. O cinema e o selo de estatística. [19--]. Disponível em: <https:// goo.gl/BiEooK>. Acesso em: 20 out. 2017.

FILME B. Quem somos. 2017. Disponível em: <https://goo.gl/BMFvnB>. Acesso em: 20 out. 2017.

FIRST Brazil film survey shows $\$ 8.000,000$ annual biz, 80\% to US distribs; language not a problem. Variety, New York, v. 121, n. 8, p. 22, 1936.

FREIRE, R. L. "A conversão para o cinema sonoro no Brasil e o mercado exibidor na década de 1930”. Significação - Revista de Cultura Audiovisual, São Paulo, v. 40, n. 40 , p. $29-51,2013$.

Cinematographo em Nictheroy: história das salas de cinema de Niterói. Niterói: Niterói Livros, 2012. 
FONSECA, A. V. M. Cinema: preços de ingressos na presente conjuntura econômica do país. Rio de Janeiro, 1955. Mimeografado.

FORTE, M. M. Município de Niterói: geografia, história e estatística. In: CONGRESSO BRASILEIRO DE GEOGRAFIA, 9., 1940, Florianópolis. Anais... Rio de Janeiro: Jornal do Commercio; Rodrigues \& Cia, 1941.

GONZAGA, A. Palácios e poeiras: 100 anos de cinemas no Rio de Janeiro. Rio de Janeiro: Funarte; Record, 1996.

INSTITUTO BRASILEIRO DE GEOGRAFIA E ESTATÍSTICA. Anuário estatístico do Brasil: ano 5 - 1939/1940. Rio de Janeiro: IBGE, 1941.

. Anuário estatístico do Brasil: ano 6 - 1941/1945. Rio de Janeiro: Serviço Gráfico do IBGE, 1946.

do IBGE, 1949.

Anuário estatístico do Brasil: ano 9 - 1948. Rio de Janeiro: Serviço Gráfico do IBGE, 1950.

Anuário estatístico do Brasil: ano 10 - 1949. Rio de Janeiro: Serviço Gráfico . Anuário estatístico do Brasil: ano 11 - 1950. Rio de Janeiro: Serviço Gráfico do IBGE, 1951.

. Anuário estatístico do Brasil: ano 12 - 1951. Rio de Janeiro: Serviço Gráfico do IBGE, 1952.

Anuário estatístico do Brasil: ano 13 - 1952. Rio de Janeiro: Serviço Gráfico $\overline{\text { do IBG }} \mathrm{E}, 1953 \mathrm{a}$.

. Anuário estatístico do Brasil - 1953: ano 14. Rio de Janeiro: Serviço Gráfico do IBGE, 1953 b.

. Anuário estatístico do Brasil - 1954: ano 15. Rio de Janeiro: Serviço Gráfico do IBGE, 1954.

Anuário estatístico do Brasil - 1955: ano 16. Rio de Janeiro: Serviço Gráfico do IBGE, 1955. do IBGE, 1957. do IBGE, 1959.

Anuário estatístico do Brasil - 1959: ano 20. Rio de Janeiro: Serviço Gráfico . Anuário estatístico do Brasil - 1960: ano 21. Rio de Janeiro: Serviço Gráfico do IBGE, 1960.

. Anuário estatístico do Brasil - 1961: ano 22. Rio de Janeiro: Serviço Gráfico do IBGE, 1961. 
do IBGE, 1962.

Anuário estatístico do Brasil - 1962: ano 23. Rio de Janeiro: Serviço Gráfico

. Anuário estatístico do Brasil - 1963: ano 24. Rio de Janeiro: Serviço Gráfico do IBGE, 1963. do IBGE, 1964

Anuário estatístico do Brasil - 1964: ano 25. Rio de Janeiro: Serviço Gráfico

Anuário estatístico do Brasil - 1965. Rio de Janeiro: Serviço Gráfico do IBGE, 1965. v. 26.

Anuário estatístico do Brasil - 1966. Rio de Janeiro: Serviço Gráfico do IBGE, 1966. v. 27.

Anuário estatístico do Brasil - 1969. Rio de Janeiro: Serviço Gráfico do IBGE, 1969. v. 30.

Anuário estatístico do Brasil - 1974. Rio de Janeiro: Serviço Gráfico do IBGE, 1974. v. 35

. Anuário estatístico do Brasil - 1976. Rio de Janeiro: Serviço Gráfico do IBGE, 1976. v. 37.

Anuário estatístico do Brasil - 1979. Rio de Janeiro: Serviço Gráfico do IBGE, 1979. v. 40.

. Anuário estatístico do Brasil - 1983. Rio de Janeiro: Serviço Gráfico do IBGE, 1983. v. 44.

. Anuário estatístico do Brasil - 1984. Rio de Janeiro: Serviço Gráfico do IBGE, 1984. v. 45.

Anuário estatístico do Brasil - 1985. Rio de Janeiro: Serviço Gráfico do IBGE, 1985. v. 46.

. Anuário estatístico do Brasil - 1986. Rio de Janeiro: Serviço Gráfico do IBGE, 1986. v. 47.

. Anuário estatístico do Brasil - 1987/1988. Rio de Janeiro: Serviço Gráfico do IBGE, 1988. v. 48.

NOBRE, F. S. Mercado de Cinema no Brasil. Rio de Janeiro: Pongetti, 1957.

REVISTA DO GEICINE. Rio de Janeiro: Geicine, n. 1, 1961.

REVISTA FILME CULTURA. Rio de Janeiro: Muniz S. A., n. 4, mar.-abr. 1967.

REVISTA SELECTA. Rio de Janeiro: Selecta, v. 11. n. 36, 5 set. 1925.

SALEM, H. Cinema brasileiro: um balanço dos 5 anos da retomada do cinema nacional. Brasília, DF: Ministério da Cultura, 1999. 
SENRA, N. C. "Os municípios na formação do IBGE”. In: (Org.). O IBGE na história do municipalismo e sua atuação nos municípios: o pensamento de Teixeira de Freitas e de Rafael Xavier. Rio de Janeiro: IBGE, 2008.

SIMIS, A. Notas sobre o “cinema independente" contemporâneo no Brasil. In: CONGRESSO IBERO-AMERICANO de COMUNICAÇÂO - IBERCOM, 14. 2015, São Paulo. Anais eletrônicos... São Paulo: ECA - USP, 2015. p. 679-687. Disponível em: <https://goo.gl/UlPGjX>. Acesso em: 20 out. 2017.

SOUZA, C. R.; FREIRE, R. L. "A chegada do cinema sonoro ao Brasil”. In: RAMOS, F.; SCHVARZMAN, S. Nova história do cinema brasileiro. São Paulo: SESC, 2017. No prelo.

SOUZA, J. I. M. Salas de cinema e história urbana de São Paulo (1895-1930): o cinema dos engenheiros. São Paulo: Senac São Paulo, 2016.

TAKAHASHI, J. Cinema brasileiro: evolução e desempenho. São Paulo: Fundação Japão, 1985.

TECHNICAL news and notes on equipment development. Business Screen Magazine, Wilmington, v. 2, n. 7, p. 28-30, 1940.

submetido em: 8 jun. 2017 | aprovado em: 5 out. 2017. 